\section{TURISMO URBANO E INTERVENÇÃO DO ESTADO}

\author{
Keila Brandão Cavalcanti ${ }^{1}$ \\ Maria das Graças de Menezes V. Paiva ${ }^{2}$
}

\begin{abstract}
RESUMO: O turismo, correspondendo à exploração organizada e comercial do lazer, exige a produção de equipamentos e serviços coletivos e, dessa forma, concorre para a produção e transformação da cidade. Assim, a política de turismo se configura como uma forma de política urbana, na qual o Estado intervém com a adoção de políticas que conciliam a preocupação do turismo com o urbano. Nesse sentido, este artigo descreve brevemente o histórico dos planos urbano-turísticos, ressaltando a experiência brasileira na área e aborda a política de turismo no Nordeste, situando essa região no contexto nacional, sob uma perspectiva histórica.
\end{abstract}

PALAVRAS-CHAVE: Turismo urbano; intervenção do Estado planos urbano-turísticos; política de Turismono Nordeste Brasileiro.

ABSTRACT: Tourism, corresponding to the organized and commercial investigation, claims for the production of equipments and collective services, this way contributing for the production and transformation of the city. By these means, the tourism politics configures itself as an urban political form, in which the State intervenes with the adoption of politics that concliate the preocupation on tourism with the urban. In this sense, this article describes briefly the historical of the urban-touristic plans, emphasizing the Brazilian experience in the areaand broaching the tourism politics of the Northeast, placing this region in the national context, under an historical perspective.

KEY WORDS: Urban tourism; intervention of the State; urban-touristic plans; tourism policy in the Brazilian Northeast.

1 Mestre e professora do Curso de Ciências Sociais da Universidade Federal do Rio Grande do Norte.

2 Professora do PPGA da Universidade Federal do Rio Grande do Norte. End. para corresp.: Rua Juvenal Lamartine, 669 - Tirol - Natal - Rio Grande do Norte - Brasil.
No Brasil, como em outros países latino-americanos, o resultado da intervenção estatal materializado nas políticas econômicas dos diferentes govemos, durante mais de meio século, produziram profundas desigualdades sociais na medida em que concentravam a propriedade, o capital, a riqueza e a renda privilegiando,apenas, uma minoria da sociedade com alto poder aquisitivo.

Essas contradições são próprias de uma sociedade capitalista subdesenvolvida e se exacerbaram no Brasil em função das particularidades históricas de sua formação social. Portanto, estas contradições nāo se dão de forma aleatória; obedecem a uma lógica coerente com o modo de produção dominante e à dinâmica interna da sociedade, bem comoà natureza e à amplitude da intervenção do Estado assumidas na formação social brasileira, manifestando-se concretamente no espaço urbano.

Neste sentido, esse processo contraditório em que se produz a cidade capitalista, no seu estágio monopolista, exige também uma interferência permanente do Estado, em qualquer dos seus níveis, como normatizador, regulador e produtor do espaço urbano (LOJIKNE, 1981:186). Esta ação estatal se insere no contexto das políticas urbanas e visa tanto a minimizar os conflitos gerados das contradições da sociedade capitalista, como a atender interesses de alguns grupos sociais.

O turismo, dentro desse contexto, não é uma atividade que passa ao largo do modo de produção capitalista, tampouco de sua expressāo espacial. O turismo corresponde à exploração organizada e comercial do lazer. Dessa forma exige a produção de equipamentos e serviços coletivos, concorrendo assim para a produção e transformação da cidade.

Neste sentido, a política de turismo se configura como uma forma de política urbana, sendo entendida como

o ato que supōe deslocamento momentâneo, com realização de gastos de renda, cujo objetivo principal é a obtenção de satisfação e serviços, que são oferecidos através de uma atividade produtiva que implica em investimentos prévios (PALOMO, 1979).

Nesta perspectiva, o Estado também intervém com a adoção de políticas que conciliam a preocupação do turismo com o urbano. Essa questão necessita ser refletida, em cujo contexto foi analisada a 
problemática dos planos urbano-turísticos, através do projeto "Parque das Dunas/Via Costeira". 3

\section{BREVE HISTÓRICO DOS PLANOS URBANO-TURÍSTICOS}

A compreensão do processo de crescimento do turismo está associada às formas de intervenção do Estado no espaço urbano. 0 turismo e a política urbana não são processos independentes. Ao contrário, respaldando-se sobre uma base territorial, o turismo, como processo de deslocamento e estada, afeta o espaço urbano que por sua vez é afetado pelas ações do Estado, que se processam no seu âmbito. Não só as ações que criam as condições da infra-estrutura urbana, mas também aquelas relativas à política de ocupação e uso do solo. Essas ações determinam o incremento da atividade turística.

Em ambos os casos, o Estado intervém estabelecendo parâmetros para a expansão do capital, através de processos urbanos de produção e reprodução. Daí advém a necessidade de se refletir sobre a representatividade da intervenção estatal no espaço urbano.

Atualmente, vive-se um período em que o turismo ressurge ligado ao apelo ecológico e à noção de qualidade de vida - tão buscado pelos países desenvolvidos no que se refere ao lazer. As modificações ocorridas na ordem econômica internacional trarão reflexos sobre as atividades turísticas, devido à reestruturação dos regimes políticos dos países do Leste Europeu e ao ingresso dos chamados Novos Países Industrializados (NICs). É importante lembrar que, embora fortemente oligopolizado, o mercado do turismo mundial registrou taxas de crescimento de $11,5 \%$ ao ano, no período de 1975 a 1987 , encontrando-se entre os três itens de maior geração de receitas de divisas.

3 Este projeto foi analisado na Dissertação de Mestrado da profa. Keila Brandão Cavalcanti, Estado e Politica de Turismo: o caso da Via Costeira em Natal e na pesquisa Análise da gestão administrativa e tecnológica de planos urbanisticos-turísticos: o caso da Via Costeira/Parque das Dunas, que contou com o apoio do CNPq.

4 Os outros dois itens são: o petróleo e a indústria automobilística.
Essas taxas de crescimento são pouco significativas para países nāo-desenvolvidos, dentre os quais o Brasil, mas detentores de vasto potencial turístico ao se considerar que $80 \%$ dos fluxos e das receitas concentram-se nos países mais desenvolvidas, conforme dados da Organização Mundial de Turismo (CASTELLI, 1986). Segundo RABAHY (1990:17-25) treze países são responsáveis pelo turismo emissivo mundial, dos quais quatro detêm $50 \%$ do fluxo emissivo: Estados Unidos, França, Alemanha e Reino Unido.

Paradoxalmente, essa etapa representa a oportunidade de inserção diferenciada do Brasil no mercado internacional do turismo. No entanto possibilidades mais positivas são de difícil alcance, haja visto o esvaziamento da política pública para o setor e a forte recessão econômica em que o país se encontra.

\subsection{O que são Planos Urbano-Turísticos}

Considera-se como planos urbano-turísticos as propostas de ocupação do solo, que se fundamentam na abertura de estradas ao longo do litoral; o zoneamento de áreas com destinações específicas e a implantação de equipamentos de consumo coletivo destinados ao lazer e ao turismo, conjugando ou não edificações residenciais.

Os primeiros planos urbano-turisticos foram implementados na Europa, após a Segunda Guerra Mundial, em função do turismo de massa que invadia de forma desordenada o litoral, tanto da Costa Azul da França (Riveira Francesa) como o da Costa Brava da Espanha, embora desde os séculos XVIII e XIX já existissem os centros e vilas destinados ao lazer da aristocracia na faixa litorânea.

As primeiras medidas de intervenção dos governos francês e espanhol procuraram evitar a desagregação ambiental, reorganizar o espaço em função do turismo, modernizar a infra-estrutura funcional e integrar o litoral da Espanha e França ao resto da Europa. Esses planos procuravam preservar as atividades tradicionais da região pesca, agricultura e indústria nativa.

Na costa do Mar Negro, litoral da Bulgária e Romênia, os govemos socialistas construíram complexos de férias coletivos de grandes dimensões para atender o turismo dos trabalhadores. 
Nos anos 60 e início dos anos 70 outras experiências aconteceram na Europa, no Oriente Médio e norte da África (MOLINA \& ABITIA, 1989; ACERENZA, 1987; PEARCE, 1988).

Em relação à América Latina, vários planos foram formulados com o apoio da Organização dos Estados Americanos (OEA). Esse apoio era financeiro e técnico, na medida em que envolvia a consultoria de "experts" que haviam participado das equipes responsáveis pelos planos europeus. A realização do "I Seminário Interamericano sobre Planificación Turística", em 1979, na Cidade do México e, sobretudo, a criação do Centro Interamericano de Capacitação Turistica (CICATUR), no México, foram passos decisivos para o desencadeamento das várias propostas, que conjugavam o turismo à ocupação do espaço urbano.

\subsection{A Experiência Brasileira}

No Brasil, como em outros países de capitalismo tardio, as políticas urbanas manifestadas através de planos urbano-turísticos não expressam uma preocupação com a reprodução da força de trabalho, prevalecendo o atendimento à reprodução ampliada da capital. O Estado, no caso, tem-se limitado a propiciar a infra-estrutura básica - abertura de estradas, iluminação pública, saneamento etc. -, a oferecer facilidades aos empresários ou grupos interessados em investir na forma de estímulos fiscais e financeiros, como a participação acionária entre outros

Um aspecto que merece ser ressaltado é que a maior parte das propostas formuladas nunca foram implementadas, em decorrência da descontinuidade administrativa dos governos, falta de recursos e até pela predominância na sociedade brasileira de um acentuado formalismo. Esses fatores correspondem à diferenciação entre o prescritivo e o descritivo, entre o poder formal e o poder efetivo, entre a impressão (que é dada pelas leis, regulamentos, planos e organogramas) e as práticas reais do governo e da sociedade (RIGS, 1966). Somam-se a esses fatores entraves oriundos da própria dinâmica do capitalismo, decorrente dos vários interesses em jogo.

No Brasil, um dos primeiros projetos dessa natureza foi o Projeto Turis (1972/1973), que procurou integrar o litoral do Rio de Janeiro a Santos (São Paulo), elaborado por uma equipe de "experts" que haviam participado da experiência francesa do Projeto Lanquedoc Roussilion e por técnicos de nacionalidade brasileira. Posteriormente, foram elaborados os seguintes projetos: o Plano Diretor da Orla marítima da Bahia - Porto Seguro, Santa Cruz da Cabrália; o Plano Porto de Barra; o Plano Açu da Torre; além do Plano de Turismo do Recôncavo. Este último foi iniciado em 1970, a partir do convênio celebrado entre o governo baiano e o consórcio CLAN/OTI.

Para SILVA (1991:199) muitas das ações realizadas na Bahia na década de 1970 foram sinalizadas pelo Plano de Turismo do Recôncavo, como a valorização da orla e a construção do centro de convençōes. No entanto, não foi respeitada a sua concepção integrativa. Essa tendência foi seguida por outros planos físicos formulados.

\section{POLITICA DE TURISMO NO NORDESTE}

É necessário, para o exame da intervenção estatal no turismo do Nordeste, situar e entender a inserção dessa região no contexto nacional, numa perspectiva histórica.

A fase que antecede a criação da Sudene - Superintendência de Desenvolvimento do Nordeste - é amplamente reconhecida como um período voltado à agricultura comercial, ou seja, para a ex portação de alguns poucos produtos, especial mente a cana-de-açúcar, o algodão e o cacau. A agricultura dominou e estruturou a vida econômica da região até décadas recentes. A partir dos anos 60 essa dinâmica foi radicalmente transformada em decorrência do processo de intervenção do Estado, inserindo a região Nordeste no contex to nacional, como geradora de divisas e fornecedora de matérias-primas agrícolas para exportação.

Neste período, a açãodo Estado privilegiava a região Centro Sul, sendo o Nordeste alvo de ações em períodos de crises, notadamente através do DNOCS - Departamento de Obras Contra as Secas para corrigir os efeitos da seca.

A partir da Segunda Guerra Mundial a economia urbana se fortaleceu com a expansão industrial do Sudeste. Esse fato fez com que o Estado criasse condições para pôr em marcha o processo de integração nacional em torno de São Paulo — seu pólo mais dinâmico. 
A ligação Nordeste-Centro Sul foi iniciada nos anos 50 com a construção da Rodovia Rio-Bahia, a melhoria das estradas estaduais e com a realização de grandes obras de engenharia. Em 1952, criou-se o BNB - Banco do Nordeste do Brasil - e, em 1953, surgiam dois órgãos municipais de turismo, em Salvador e Recife, que marcam os estímulos da expansão capitalista no turismo.

Com a implantação da SUDENE, em 1959, sinalizou-se importantes diretrizes que iriam modificar o quadro econômico regional, notadamente a intensificação dos investimentos industriais. Para a concretização das políticas propostas pela SUDENE, foram elaborados quatro Planos Diretores: I PD (1961/1963), II PD (1963/1965), III PD (1966/1968) e IV PD (1969/1973), considerados essencialmente industrializantes.

A opção pela perspectiva de desenvolvimento industrial teve maior expressão com os incentivos fiscais instituídos pelo Congresso Nacional, no artigo 34 do I PD, que possibilitava a dedução de 50\% dos impostos devidos à União, para que as empresas de capital 100\% nacional investissem no Nordeste. Posteriormente, no artigo 18 do II $\mathrm{PD}$, em face, naturalmente, das pressōes das empresas transnacionais, esses incentivos foram estendidos a qualquer empresa, suprimindo restrições ao capital estrangeiro. A concessão desses incentivos, que ficou popularizada como mecanismo 34/18, assumiu importância decisiva na condução da política para a região, expressando o caráter da intervenção estatal, sobretudo no período após 1964

No setor de turismo, os dados existentes comprovam o crescimento da atividade na região: a rede hoteleira apresenta índices de crescimento de 4,3\%, de 1960 a 1966. De acordo com uma pesquisa realizada pelo BNB em 1971, o movimento turístico nas capitais nordestinas, de Fortaleza até Salvador, durante o mês de julho de 1971, revelou um incremento de $48 \%$ em relação ao de julho de 1968 . No período de 1966 a 1977, no tocante aos incentivos do mecanismo $34 / 18$, cerca de 37 hotéis foram implantados, sendo 14 na Bahia, 8 em Pernambuco e o restante nos demais Estados. As rodovias construídas no pós-64, que permitiram a dinamização do turismo da região e a integração ao território nacional foram as seguintes: BR-101, BR-316, BR-235, BR-110, BR-304 e BR-222. A partir do governo Geisel, o padrão de acumulação se deslocou para o setor de bens de produção, freiando os investimentos em infra-estrutura.
Além disso, o II PND - II Plano Nacional de Desenvolvimento _reconhecendo o quadro social resultante das políticas dos governos -, recones, tentou dar uma nova ênfase ao desenvolvimento brasileiro. anterior desse momento, o Nordeste e, especialmente, o turismo A pareram uma atenção especial, em decorrência da atuação estatal recevilegiar "as potencialidades regionais". Nesse sentido, o turismo do Nordeste passou a ser concebido como uma possibilidade de política de desenvolvimento regional, a partir da ocupação da faixa litorânea - considerada a grande atração turística. Assim foram iniciados os "planos urbano-turísticos", como também passou a ser feita uma ocupação mais planejada da orla marítima, no tocante aos investimentos turísticos.

Além das açōes no Estado da Bahia, abrangendo três zonas bem diferenciadas - Salvador, Litoral Nordeste, Ilha de Itaparica e Ilha de Tinharé - outras capitais nordestinas desencadearam esforços governamentais no sentido de abrir novas perspectivas econômicas à cidade, como também de atender aos interesses setoriais, que negativamente afetaram a mudança do padrão de acumulação dessas capitais. Dentre elas destacam-se Maceió (AL) e Natal(RN), esta última com o projeto Parque das Dunas/Via Costeira. Recentemente, surgiram propostas dos governos da Paraiba - o Projeto Costa do Sol, de Pernambuco e Alagoas; do Rio Grande do Norte - o Projeto Costa Dourada; e, finalmente, o Prodetur, que integra todos os Estados Nordestinos.

No campo institucional, atendendo às exigências de modernização e centralização do Estado, um amplo leque de açōes foram emprendidas, no sentido de criar uma estrutura organizacional capaz de suprir as necessidades da dinâmica da economia nordestina. No setor de turismo, implantaram-se inúmeros organismos com oobjetivo específico de se ocuparem desta atividade, sem contudo obedecerem a uma padronização.

\section{CONSIDERAÇÕES FINAIS}

O turismo, neste momento de crise, além de atender determinadosinteresses privados, significa uma razoável alternativa econômica, pelas seguintes razōes: 
a) baixo custo de capital por unidade produzida, uma vez que não implica em máquinas e equipamentos de alto custo para entrar em operação, diferentemente da indústria;

b) o período de maturação dos investimentos é mais rápido em comparação com outras atividades econômicas, visto que o empreendjmento só funciona com a conclusão da estrutura física e os recursos humanos treinados;

c) utilizam-se recursos materiais, humanos e financeiros locais, entre outros.

Com o crescimento do turismo, o Nordeste ganhou uma nova configuração. Suas capitais adquiriram um novo "visual", transparecendo uma imagem de modernidade inquestionável. Não obstante essa imagem positiva, os empregos e a renda gerados pelo turismo não alteraram o quadro social desalentador que os indicadores sociais apontam. Como conseqüência desse crescimento, encontra-se um "aquecimento" no setor informal - na forma de empregos não-fixos, sem carteira assinada; o pequeno comércio das "barracas" de comidas e bebidas típicas, localizadas nas praias do litoral, além das atividades decorrenies da produção e comercialização do artesanato.

Isto denuncia a natureza concentradora da expansão capitalista, que se alastrou pelo Brasil, avançando sobre o Nordeste, no contexto de um amplo processo de agregação dos diversos espaços econômicos.

\section{REFERÊNCIAS BIBLIOGRÁFICAS}

ACERENZA, Miguel A. 1987. Administração del turismo. Planificación e direción. México: Trillas. v.II

CASTELLI, Geraldo. 1986. Turismo - Atividade marcante do século XX. Porto Alegre, UCS.

MOLINA, Sérgio \& ABITIA, Sérgio R. 1989. Planificación integral del turismo: um enfoque na América Latina. México: Trillas.

LOJIKNE, Jean. 1981. O Estado capitalista e a questão urbana. São Paulo: Martins Fontes.

PALOMO, Miguel F. 1979. Economia Turística. Madrid. (Tese de Doutorado).

PEARCE, Douglas. 1988. Desarrollo turístico - su planificación y ubicación geográficas. México: Trillas.
RABAHY, Wilson. 1990. Planejamento do mentos econométricos. São Paulo: Loyola.

RIGS, Fred W. 1966. A ecologia da administração pública. Rio de Janeiro: Fundação Getúlio Vargas.

SILVA, Jorge Antônio Santos. 1991. O desempenho do turismo em Salvador. Bahia: Escola de Administração/UFBA. 